\title{
Integrated marketing communications: a strategic priority in health and medicine
}

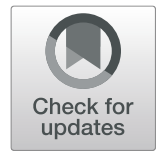

James K. Elrod ${ }^{1}$ and John L. Fortenberry Jr. ${ }^{1,2^{*}}$

\begin{abstract}
Background: Healthcare establishments portray themselves to their patient populations using many communicative mechanisms. Perhaps the first avenues that come to mind are the outward conveyances of the marketing communications mix, including advertising, personal selling, sales promotion, public relations, and direct marketing. But other prominent communicators also exist, including the people employed by healthcare institutions, the places in which services are delivered, and the brands that represent given establishments. This wide variety of communicative mechanisms is somewhat of a mixed blessing, affording myriad options, but also necessitating extra care and attention in developing associated marketing communications.

Discussion: Now more than ever, health and medical establishments have at their disposal communications options capable of addressing most any conveyance want or need. The marketing communications mix, once somewhat limited due to industry tradition, is now fully accessible and widely used in the health services industry, providing immense opportunities to connect with patients. Options for signage, building designs, servicescape amenities, employee uniforms, and the like also are teeming, providing myriad avenues for making positive impressions. But burgeoning options while beneficial also intensify obligations for ensuring that marketing communications are properly integrated, with this particular article describing this imperative need and its implications for communicative success in the healthcare industry.

Conclusions: By integrating marketing communications, health and medical providers are able to create synergies between and among selected conveyance mechanisms, amplifying performance and increasing the likelihood of reaching communicative goals. Achieving such cohesion requires devoted planning in an effort to coordinate verbal and visual manifestations to express desired imagery and appeals to target audiences. As extensive benefits are derived from integrated marketing communications, healthcare establishments should consider associated pursuits to be a strategic priority.
\end{abstract}

Keywords: Integrated marketing communications, Promotion, Advertising, Hospitals, Healthcare

\section{Background}

Communicating successfully with current and prospective patients represents an essential and ongoing task for health and medical establishments [1-3]. Excellence on this front is vital for many reasons, with perhaps the most

\footnotetext{
* Correspondence: john.fortenberry@lsus.edu

${ }^{1}$ Willis-Knighton Health System, 2600 Greenwood Road, Shreveport, LA 71103, USA

${ }^{2}$ LSU Shreveport, 1 University Place, Shreveport, LA 71115, USA
}

notable being that effective communications inform and enlighten audiences, generating interest and attention, prerequisites for attracting patients and acquiring market share [2, 4-6]. Communications, of course, must be appealing to target markets, necessitating steps to ensure positive portrayals at every opportunity, with healthcare establishments turning to many promotional mechanisms to engage desired patient populations. In such pursuits, perhaps the first avenues that come to mind are the outward conveyances of advertising, public relations, sales

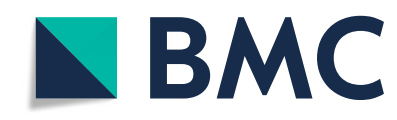

(c) The Author(s). 2020 Open Access This article is licensed under a Creative Commons Attribution 4.0 International License, which permits use, sharing, adaptation, distribution and reproduction in any medium or format, as long as you give appropriate credit to the original author(s) and the source, provide a link to the Creative Commons licence, and indicate if changes were made. The images or other third party material in this article are included in the article's Creative Commons licence, unless indicated otherwise in a credit line to the material. If material is not included in the article's Creative Commons licence and your intended use is not permitted by statutory regulation or exceeds the permitted use, you will need to obtain permission directly from the copyright holder. To view a copy of this licence, visit http://creativecommons.org/licenses/by/4.0/. The Creative Commons Public Domain Dedication waiver (http://creativecommons.org/publicdomain/zero/1.0/) applies to the data made available in this article, unless otherwise stated in a credit line to the data. 
promotion, and other components of the traditional marketing communications mix, with these pathways being traversed extensively by health and medical organizations in bids to connect with audiences $[2,4,7,8]$.

Indeed, the components of the marketing communications mix are tried and true methods for engaging patient populations, but they are not the only avenues available for doing so. Other prominent communicators also exist, including the people employed by healthcare institutions, the places in which services are delivered, and the brands that represent given establishments, affording extended means for informing and enlightening customer groups $[2,4,7,9-12]$. This wide variety of communicative mechanisms, however, is somewhat of a mixed blessing. While the burgeoning array of options affords tremendous utility, healthcare providers must direct extra care and attention when assembling associated conveyances to ensure cohesion between and among promotional elements. Such cohesion yields integrated marketing communications which should be a strategic priority for health and medical establishments. This particular article shares a range of insights on integrated marketing communications, providing useful guidance for healthcare organizations seeking to bolster their patient engagement efforts.

\section{Discussion}

Now more than ever, health and medical establishments have at their disposal communications options capable of addressing most any conveyance want or need. Today, healthcare institutions routinely make use of the full marketing communications mix, calling upon its five components of advertising, personal selling, sales promotion, public relations, and direct marketing as desired to reach their target audiences $[2,4,13]$. This starkly contrasts with prevailing healthcare industry mindsets of the not-sodistant past (ca. 1980s and earlier) which frowned on using the full power of the marketing communications mix. Notably, advertising was viewed to be beneath the dignity of medical providers and potentially detrimental to established patient referral patterns. But associated resistance ended in the 1980 s, aided notably by governmental scrutiny of the American Medical Association's ban on its members' use of advertising, paving the way for advertising to flourish, making the marketing communications mix fully accessible and acceptable for use in the health services industry $[1,5,7,9]$.

Beyond the components of the marketing communications mix, foundational elements-people, places, and things that communicate on behalf of healthcare institutions-also present more opportunities than ever to make positive, enduring impressions. Cutting edge training programs, stylish uniforms, and the like have the potential to dramatically elevate the actions and appearances of healthcare personnel; modern exterior and interior signage options, especially digital variants, are capable of capturing attention like never before; and contemporary servicescape designs and associated amenities have the power to greatly impress and inspire target audiences. These and similar elements convey volumes of information to others, arguably projecting details as robustly as anything within the traditional marketing communications mix, crucially impacting the perspectives of current and prospective patients and presenting immense opportunities to influence associated patronage decisions $[2,4$, 7, 9-12].

But burgeoning communicative options, while beneficial, also intensify obligations for ensuring that marketing communications deployed by given healthcare institutions are properly integrated to present a cohesive picture to target audiences. Integrated marketing communications (IMC) happens to be a formal term in the discipline of marketing. It is defined as "the coordination of all of the marketing communications efforts of an organization for the purpose of ensuring the consistent presentation of promotional messages to target audiences" [2], p. 286. Essentially, achieving integrated marketing communications yields a highly-desired communicative state where all conveyances telegraphed by an establishment over a given period of time are linked together. This typically is realized through the use of a defined collection of verbal and visual manifestations (e.g., logos, slogans, color schemes, themes), leading audiences to view each communication to be part of a comprehensive body of work presenting the establishment clearly and cohesively. Integration effectively creates synergies between and among all of the promotional elements deployed by an organization, amplifying the impact potential of communicative efforts $[2,4,14-16]$.

In the absence of such integration, communicative elements lack effective linkages. Imagine, for example, a scenario where a healthcare establishment, on adopting a new slogan, updates its advertising to feature the new expression, but neglects to revise its other promotional materials, accordingly. Similarly, consider a situation where corporate colors have been updated, but some marketing communications continue to make use of the former color array. Given different creative treatments, communicative synergies cannot be leveraged, diminishing impact that otherwise would be possible via proper communicative integration. Indeed, the necessity for integrating marketing communications is so pronounced that entire textbooks have been written on the topic (e.g., [17-21]), demonstrating its associated value and importance.

Achieving a marketing communications presence that would be considered to be integrated requires extensive attention to detail. As various forms of promotion are 
developed, efforts must be directed toward ensuring that they work in harmony together, creating a cohesive, interrelated body of work [2, 4]. As content which portrays healthcare establishments (e.g., signage, advertisements, sales promotions, websites, stationery, direct mail) usually is produced over time, the need for vigilance is quite obvious, as without such, incongruence can appear in the verbal and visual artifacts representing institutions, undermining efforts to achieve and maintain integration between and among components. Such incongruence can range from subtle (e.g., an updated font for use on business cards and letterhead is introduced, but stationery featuring the old font continues to be circulated) to very obvious (e.g., a logo is revised, but signage continues to display the former identity), with such inconsistencies, regardless of magnitude, undermining communicative power and potential [4].

To foster presentation of a consistent image across all marketing communications, health and medical establishments can benefit by developing a creative style guide, a comprehensive marketing communications document which presents depictions of approved verbal and visual elements representing given institutions and supplies detailed guidelines for their use. The exact composition of such guides is dependent on the wants and needs of given healthcare establishments, but typical areas that are addressed include (1) logos, noting their proper display, use, and associated restrictions, (2) creative treatments, outlining approved typography, color schemes, and associated stylistic elements, (3) messaging characteristics, noting approved slogans, storylines, and related content, (4) audience profiles, indicating served markets, associated targets, and demographic attributes, (5) communication avenues, identifying components of the marketing communications mix and any supplementary communications pathways that are to be pursued, and (6) authorization processes, outlining protocols for presenting assembled communications to institutional leaders for review and approval, permitting dissemination.

The activity of developing these guides, in and of itself, is helpful in that it forces institutional leaders to think deeply on the verbal and visual manifestations which represent their given organizations, providing an opportunity to examine and potentially improve methods and manners of presenting their establishments to target audiences. This also aids in achieving communicative cohesion, as components are developed in an orderly fashion, something which avoids patchwork assembly methods which inadvertently can foster incongruity $[2,4,10,22]$. The all-important authorization process is also addressed, further ensuring compliance with designated standards. By adhering to defined creative protocols, a clear identity emerges, essentially yielding consistent creative signatures which amplify all marketing communications forwarded on behalf of healthcare institutions.

In the 1970s, a particularly formative time period for the institution, Willis-Knighton Health System laid the groundwork for enduring integrated marketing communications by focusing on creative treatments and applications, with one of the most essential being the development of an appealing logo. Today, this logo is
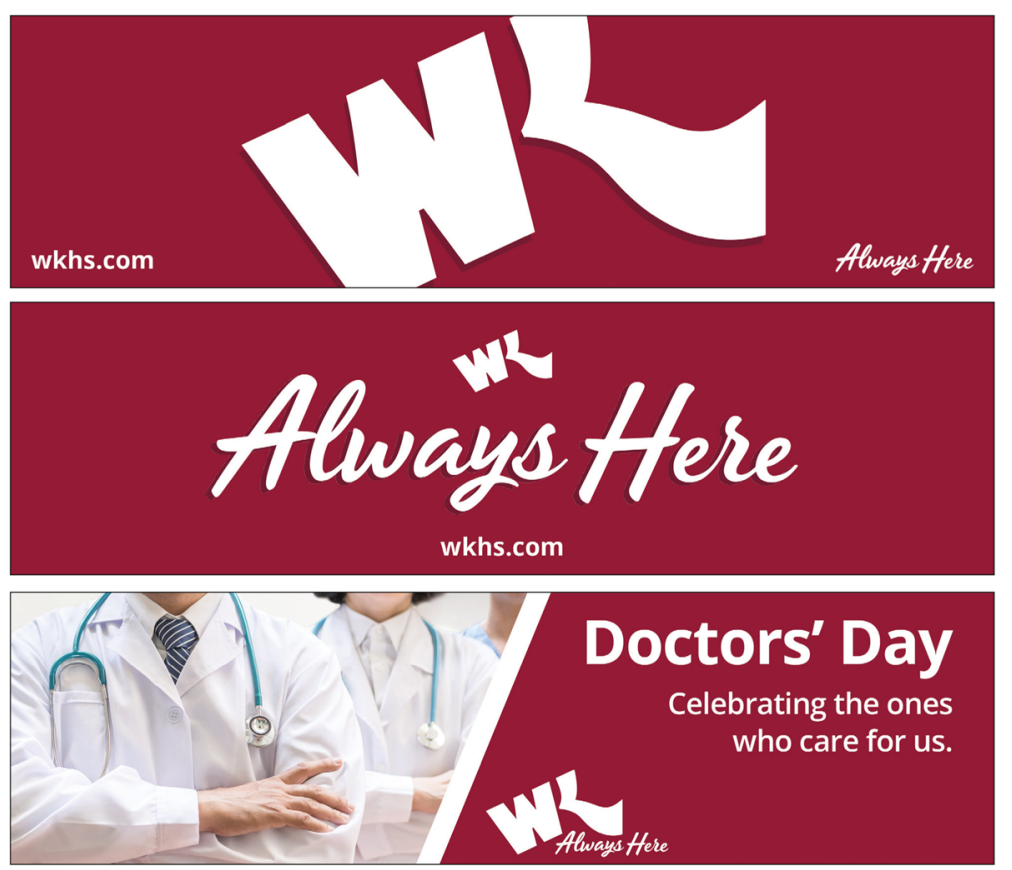

Fig. 1 Several recent billboard advertisements promoting Willis-Knighton Health System 
one of the most widely recognized in the marketplace and it anchors virtually every communication forwarded by the institution $[9,10]$. Coupled with consistent color schemes, slogans, and manners and methods of presentation, Willis-Knighton Health System's particular creative treatment, regardless of the service line to which it is applied, builds communicative bridges between and among each and every conveyance, naturally supplying the critical linkages that afford integrated marketing communications, as the sample billboard and newspaper advertisements, provided in Figs. 1 and 2, and the

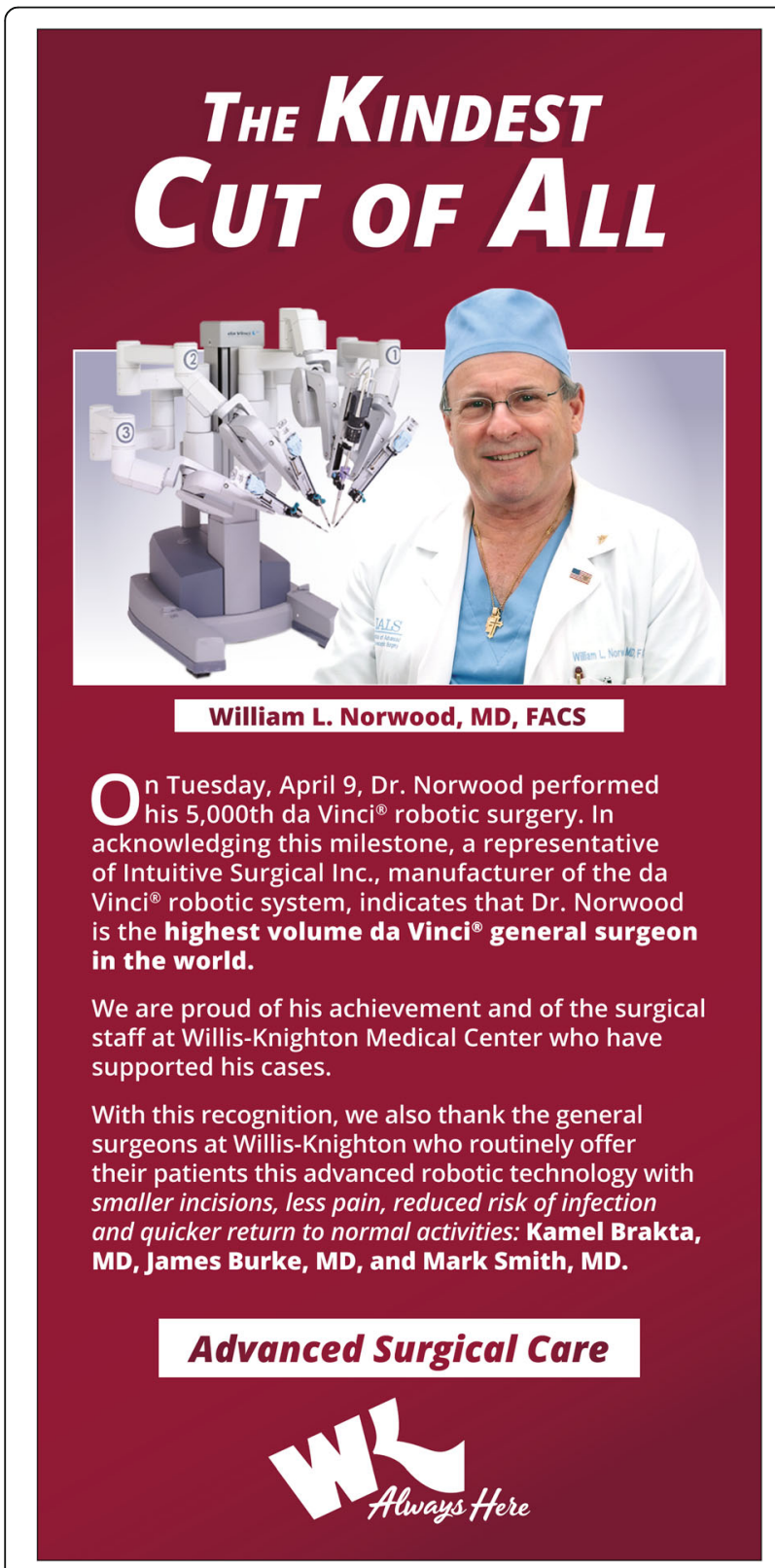

Fig. 2 A recent newspaper advertisement promoting Willis-Knighton Health System sample television commercials, available at https://www. wkhs.com/video/commercials, illustrate.

Applications of Willis-Knighton Health System's creative style are not limited to conveyances of the traditional marketing communications mix; they influence decisions pertaining to anything which communicates on behalf of the institution, guiding signage decisions, employee uniform designs, and so on, yielding a universal creative portrayal of the institution to its audiences. Such results stem from the devoted use of a creative style guide which, once assembled and approved, directs the development and dissemination of content, providing reasonable assurances that presentations and portrayals of given institutions will be consistent.

A healthcare establishment's achievement of integrated marketing communications is best ascertained by viewing the totality of communicative elements deployed by the given institution. Interior and exterior signage, stationery, employee uniforms, promotional brochures, advertisements, direct mail pieces, website designs and associated promotional content, and more should be examined comprehensively. If each element when viewed individually appears to be part of the larger body of work, then integration pursuits can be deemed to have been successful. If not, corrective actions need to be taken to bring noncompliant promotional elements into compliance with the communicative aims expressed in the associated creative style guide, affording harmony between and among all conveyances.

While the concept of integrated marketing communications might seem so obvious as to not warrant discussion, environmental complexities, propensities to lose sight of the bigger picture, routine distractions, and the like have the potential to undermine and erode efforts to ensure cohesion between and among communicative components. As noted earlier, if proper attention is not directed toward the assembly and management of elements promoting healthcare establishments, incongruence eventually will emerge, diminishing the communicative power and potential of given expressions. The introduction and use of creative style guides, coupled with ongoing discussions regarding the importance of integrated marketing communications, will help healthcare establishments stay on course for achieving harmony across all communications, reaping associated benefits.

\section{Conclusions}

By integrating marketing communications, health and medical providers are able to portray themselves clearly and consistently to their audiences, something that is absolutely essential for the best communicative outcomes. Further, synergies will emerge between and among the deployed conveyance mechanisms, amplifying performance and increasing the likelihood of reaching communicative 
goals, ultimately improving the return on investment generated by the associated marketing communications. Achieving such cohesion requires devoted planning in an effort to coordinate verbal and visual manifestations to express desired imagery and appeals to target audiences, with guiding protocols and reminders to maintain integration being essential as a defense against oversights and distractions which could lead to communications incongruence. As extensive benefits are derived from integrated marketing communications, healthcare establishments should consider associated pursuits to be a strategic priority.

\section{Acknowledgments}

A special note of thanks is extended to Marilyn Joiner, Darrell Rebouche, and the greater Willis-Knighton Health System family for their helpful assistance throughout the development and publication of this article.

\section{About this supplement}

This article has been published as part of BMC Health Services Research Volume 20 Supplement 1, 2020: Marketing communications in health and medicine: perspectives from Willis-Knighton Health System. The full contents of the supplement are available online at http://bmchealthservres.biomedcentral.com/articles/supplements/volume-20-supplement-1.

\section{Authors' contributions}

The authors jointly developed the submitted manuscript, with each performing critical roles from early conceptualization through to the production of the full manuscript. The manuscript resulted from a collaborative effort. Both authors read and approved the final manuscript.

\section{Authors' information}

JKE is President and Chief Executive Officer of Shreveport, Louisiana-based Willis-Knighton Health System, the region's largest provider of healthcare services. With over 55 years of service at the helm of the institution, JKE is America's longest-tenured hospital administrator. A fellow in the American College of Healthcare Executives and honoree as a Louisiana Legend by Friends of Louisiana Public Broadcasting, he holds a bachelor's degree in business administration from Baylor University, a master's degree in hospital administration from Washington University School of Medicine, and an honorary doctorate of science and humane letters from Northwestern State University of Louisiana. He is the author of Breadcrumbs to Cheesecake, a book which chronicles the history of Willis-Knighton Health System.

JLF Jr. is Chair of the James K. Elrod Department of Health Administration, James K. Elrod Professor of Health Administration, and Professor of Marketing in the College of Business at LSU Shreveport where he teaches a variety of courses in both health administration and marketing. He holds a BBA in marketing from the University of Mississippi; an MBA from Mississippi College; a PhD in public administration and public policy, with concentrations in health administration, human resource management, and organization theory, from Auburn University; and a PhD in business administration, with a major in marketing, from the University of Manchester in the United Kingdom. He is the author of six books, including Health Care Marketing: Tools and Techniques, 3rd Edition, published by Jones and Bartlett Learning. JLF Jr. also serves as Vice President of Marketing Strategy and Planning at Willis-Knighton Health System.

\section{Funding}

Article processing charges were funded by Willis-Knighton Health System.

\section{Consent for publication}

Figures 1 and 2 are published with permission of Willis-Knighton Health System. All required approvals for publication were obtained.

\section{Competing interests}

JKE and JLF Jr. are both employed with Willis-Knighton Health System.

Published: 15 September 2020

\section{References}

1. Berkowitz E. Essentials of health care marketing. 4th ed. Burlington: Jones and Bartlett; 2017

2. Fortenberry JL Jr. Health care marketing: tools and techniques. 3rd ed. Sudbury: Jones and Bartlett; 2010.

3. Elrod JK, Fortenberry JL Jr. Healthcare establishments as owner-operators of digital billboards: making the most of excellent roadside visibility and high traffic counts to better connect with patients. BMC Health Serv Res. 2018; 18(Suppl 3):928.

4. Fortenberry $\mathrm{JL} \mathrm{Jr}$. Cases in health care marketing. Sudbury: Jones and Bartlett; 2011

5. Thomas RK. Marketing health services. 3rd ed. Chicago: Health Administration Press: 2014

6. Kotler P, Shalowitz J, Stevens RJ. Strategic marketing for health care organizations: building a customer-driven health system. San Francisco: Jossey-Bass; 2008

7. Elrod JK, Fortenberry JL Jr. Formulating productive marketing communications strategy: a major health system's experience. BMC Health Serv Res. 2018;18(Suppl 3):926.

8. Elrod JK, Fortenberry JL Jr. Catalyzing marketing innovation and competitive advantage in the healthcare industry: the value of thinking like an outsider. BMC Health Serv Res. 2018;18(Suppl 3):922.

9. Elrod JK. Breadcrumbs to cheesecake. Shreveport: R\&R Publishers; 2013.

10. Elrod JK, Fortenberry JL Jr. Driving brand equity in health services organizations: the need for an expanded view of branding. BMC Health Serv Res. 2018:18(Suppl 3):924.

11. Fortenberry JL Jr, McGoldrick PJ. Internal marketing: a pathway for healthcare facilities to improve the patient experience. Int J Healthc Manag. 2016;9(1):28-33.

12. Elrod JK, Fortenberry JL Jr. Am I seeing things through the eyes of patients? An exercise in bolstering patient attentiveness and empathy. BMC Health Serv Res. 2018;18(Suppl 3):929.

13. Fortenberry JL Jr. Nonprofit marketing. Burlington: Jones and Bartlett; 2013.

14. Laurie S, Mortimer K. How to achieve true integration: the impact of integrated marketing communication on the client/agency relationship. J Mark Manag. 2019;35(3/4):231-52.

15. Keller KL. Unlocking the power of integrated marketing communications: how integrated is your IMC program? J Advert. 2016;45(3):286-301.

16. Luxton S, Reid M, Mavondo F. Integrated marketing communication capability and brand performance. J Advert. 2015;44(1):37-46.

17. Percy L. Strategic integrated marketing communications. 3rd ed. New York: Routledge; 2018.

18. Juska JM. Integrated marketing communication: advertising and promotion in a digital world. New York: Routledge; 2018.

19. Andrews JC, Shimp TA. Advertising, promotion, and other aspects of integrated marketing communications. 10th ed. Boston: Cengage; 2018

20. Clow KE, Baack D. Integrated advertising, promotion, and marketing communications. 8th ed. New York: Pearson; 2018.

21. Moriarty S, Mitchell N, Wood C, Wells WD. Advertising and IMC: principles and practice. 11th ed. New York: Pearson; 2019.

22. Calder BJ, Reagan SJ. Brand design. In: lacobucci D, editor. Kellogg on marketing. New York: Wiley; 2001

\section{Publisher's Note}

Springer Nature remains neutral with regard to jurisdictional claims in published maps and institutional affiliations.

Availability of data and materials

Not applicable. 